\title{
Linguistic Analysis of the Phenomenon of Language Transfer
}

\author{
Asst. Lecturer: Aras Abdalkarim Amin \\ Department of English Cihan University/ Sulaimaniya
}

\begin{abstract}
When people communicate in the target language they use the linguistic competence that they have acquired or gained through the process of learning or exposure to the target language. In certain cases, people use the various linguistic resources when they perform that target language due to certain attributes and strategies. This is called language transfer which means the use and application of the knowledge of one language into the other. The current study aims at clarifying the phenomenon of language transfer theoretically by illustrating what language transfer is, the linguistic evidences of its occurrence and the possible linguistic factors which lead to its occurrence. The study reveals that language transfer occurs when people try to communicate in the target language due to specific linguistic factors including lack of linguistic knowledge which comprises various levels of language use.
\end{abstract}

Key Words: Language Transfer, Target Language, Performance, Lack of Linguistic Knowledge

\section{INTRODUCTION}

When people learn or acquire a second language for academic or other purposes, they attempt at using this target language through their progress and development in the process of language acquisition at various communicative events. But what can be noticed in certain situations is the fact that people or learners resort to their native language as linguistic resources in the performance of the target language. So people may use their knowledge of one language into another so as to communicate. This is called language transfer and comprises various levels of linguistic transfer. The paper aims at illustrating this phenomenon theoretically focusing on the possible levels of linguistic transfer and why it may occur while communicating in the target language. The study also shows some of the studies related to language transfer so as to have an efficient understanding of this significant phenomenon.

\section{LANGUAGE TRANSFER}

Basically, the term transfere means that an influence of an existing experience is exerted directly and clearly on acquiring a new knowledge. When people experience or try to acquire new things, they usually resort to existing mental sets which are largely determined by culture-specific knowledge. People with various cultural backgrounds may be influenced by such mental sets (Helen Spencer-Oatey, 2000). Therefore; communication between individuals from different cultural backgrounds may be influenced by their different mental sets. In some cultures, for example, an offer of coffee after a meal is generally recognized as a polite way to indicate to the guests that they need to leave soon if there is no intention to outstay. But such a cultural illustration might be totally different in other cultures where the same situation might reflect the host's kindness and even an indirect offer to Outstay (Ibid.). As far as language is concerned, Crystal (2003, P. 471) states that, transfer is "peculiar to foreign language learning and can be manifested notably as the influence of the person's first language on the language being acquired. Yet, the influence of the L1 on the performance of L2 is mostly considered negative as it makes learners transfer L1 features which is different from L2 and this is why such transfer is negative and it may make the L2 expressions difficult to understand". Consequently, language transfer is phenomenon that occurs in the performance of a target language in or after the process of learning or acquiring that language. This is also called L1 interference, linguistic interference, and cross linguistic influence all of which refers to language transfer. Mainly this phenomenon can be defined as the attempt of the learners or speakers to apply knowledge from one language to another language (Weinreich, 1953). In general, it is the transfer of linguistic resources (syntactic structures, grammatical features, meanings and so on) between languages in the speech range of a bilingual or multilingual individual, whether from first to second, second to first or many other relationships. It is most commonly discussed in the context of English language learning and teaching, but it can occur in any situation when someone does not have a native-level command of a language, as when translating into a second language. This means that language transfer is entirely due to lack of linguistic knowledge (Jarvis \& Pavlenko, 2008). 


\section{TYPES OF LANGUAGE TRANSFER}

Mainly, there are two types of transfer: Positive and Negative. (Richards \& Schmidt 2013, p, 607) stated that "Positive transfer is learning in one situation which helps or facilitates learning in another later situation. Negative transfer is learning in one situation which interferes with learning in another later situation." When the relevant transferred structure of both languages is the identical, linguistic transfer can result in correct language performance called positive transfer: here, the "correct" meaning is in line with most native speakers' notions of acceptability. On the other hand, language interference is most often discussed as a source of deviation and this is called negative transfer, which occurs when speakers or learners transfer items and structures that are not the same in the target language that they are after. This indicates that learners or speakers lack certain linguistic knowledge when they perform the target language in various communicative situations. For example, in English, a preposition is used before a day of the week: "I'm going to the beach on Friday." in Spanish, instead of a preposition the definite article is used. Spanish students who are native English-speakers may produce a transfer error and use a preposition when it is not necessary because of their dependence on English. According to Whitley (2002), it is natural for students to make such errors based on how the English words are used. But the most important type of transfer is the negative one as it is used largely by learners or speakers when performing the target language in addition to being an essential source in identifying the sources of deviation in language performance. Negative transfer is a kind of linguistic strategy or language process whereby learners transfer improperly the language features of their language into the target one that they are trying to perform, acquire or learn. Most noticeably, the phenomenon of language transfer within the study of the learner language has been a growing source of concern in pragmatics in recent years. The pragmatic perspective toward the learner language led to the birth of a new interdiscipline, interlanguage pragmatics (ILP) and can be defined as: "the branch of second language acquisition research which studies how non-native speakers (NNS) understand and carry out linguistic action in the target language, and how they acquire second language pragmatic knowledge" (Kasper,1992, p. 203). Accordingly, studies in interlanguage pragmatics (ILP) would focus on pragmatic performance such as skills of conversational management and support, as exemplified by turn-taking and backchannel mechanisms, address terms, politeness markers as well as non-verbal communication patterns besides presuppositions, reference, and deixis. One of the most important issues that ILP would be greatly concerned with is the negative pragmatic transfer issue, yet, there is no clear comprehensive view of its nature; there are some disagreements among the linguist as far as presenting a unified view of the nature of pragmatic transfer (ibid). After thorough and profound discussions, Kasper (1992) concludes that negative transfer occurs as a result of the effects of the pragmatic knowledge being exploited by learners; such exploitation belongs to languages and cultures other than the target language when they approach the comprehension, production and learning of pragmatic norms of the target language. As Leech (1990, p. 231) states, "Transfer of the norms of one community to another community may well lead to pragmatic failure, i.e., breakdown in communication, and to judgment that the speaker is in some way being impolite".

This simple and straightforward definition means that negative pragmatic transfer takes place in a number of different kinds of influence from languages other than the L2 and this includes avoiding the use of target language forms by non-native speakers (Ellis, 1994). Relying on the discussion above, an overall view of defining negative pragmatic transfer would contain the following main manifestation; First: The transference of performance knowledge from the native language into the target or second one. Second: The transference is negative as there are differences between the pragmatic knowledge of the L1 and that of the TL. The most important comment about such manifestations is to look for the reasons that lead to such negative pragmatic transfer. So transfer is not limited to certain level of linguistic knowledge but may vary according to the transferred item.

\section{FACTORS OF LANGUAGE TRANSFER}

To transfer the pragmatic knowledge in addition to the knowledge of other linguistic levels of the native language when trying to perform the target language is certainly an improper process because of the differences of the pragmatic knowledge and various of other linguistic knowledge and culture of the two languages and, hence, misunderstandings or miscommunications may frequently occur. But why does negative pragmatic transfer occur? This section attempts to thoroughly answer this question by surveying theoretically the major reasons that lead to negative pragmatic transfer. The most influential reason that leads to negative pragmatic transfer is the fact that learners are unaware of the pragmatic knowledge of the target language or basically they lack such linguistic knowledge. Even fairly advanced learners make pragmatic errors such that they fail to convey or understand the intended message because of lack of awareness of pragmatic rules governing the TL or due to the lack of linguistic proficiency to convey the necessary or the required acts in different situations. This clearly means that learners or interactants from different backgrounds are unaware of the differences between the pragmatic norms and knowledge which are part of their L1 mentality and the pragmatic norms and knowledge of the TL that they attempt to perform and, hence, they transfer various 
situations pragmatically which are found in their $\mathrm{L} 1$ and perform them in the TL not considering the differences between the two languages (Hellen spencer-Oatey). Although it is customary to study pragmatic transfer in the context of second language acquisition, it is relatively independent of language because pragmatic knowledge is distinct from, although it interfaces with, linguistic knowledge (ibid). To illustrate this decisive point, (Helenspence-Oatey) discusses the difficulties that East Germans have in job interviews conducted by prospective West German employer: first. Interviewer: and with your boss? Did you ever have well any argument? No, Applicant: never. Second. Interviewer: because you got on with him so well applicant: no, that's got nothing to do with it. I'm respectful (ibid, p. 167). From the point of view of the East German applicant, being respectful is a very desirable quality. The pragmatic (i.e. communicative) competence of the applicant which has been shaped by life in east Germany is transferred to a situation in which successful impression management presupposes a set of cultural values which the applicant is blissfully unaware of (ibid). This is an example of pragmatic transfer within a single language. Even fairly advanced language learners' communicative acts regularly contain pragmatic errors, or deficits, in that they fail to convey or comprehend the intended illocutionary force or politeness value which is another influential reason for negative pragmatic transfer (BlumKulka, House, \& Kasper, 1989). In fact, failure to learn what is appropriate to say in a particular situation and how to say it is likely to lead to transfer. 'Communication breakdowns' can occur, when the speaker's intention is not understood by the addressee, while 'communication conflicts' can arise when such a misunderstanding can lead to actual friction between interactants. Communication conflicts are most likely to occur where the misused language function threatens the dignity of the individual on issues of power, trust, and solidarity (ibid.).the other reason for negative pragmatic transfer is related to cultural information.

Lack of culturally relevant information, irrespective of linguistic proficiency, leads to negative transfer (Franch, 1998). The consequence of this pragmatic transfer is the fact that misunderstandings are likely to occur and they involve the carryover of culture-specific knowledge from a situation of intra-cultural communication to a situation of intercultural communication.

\section{CONCLUSION}

Transfer perhaps is the most important concept in the practice and theory of education. In fact, the principle of transfer refers to the hypothesis that first language will affect target language. The phenomenon of transfer happens when acquiring a new language is influenced by pronunciation, grammar or any other aspects of a learner's first language. By many theoreticians and teachers it is accepted that when learners attempt at communicating in foreign or second language, they often transfer some elements of their mother tongue onto patterns of the target language in both speaking and writing. So learners may use their knowledge of one language into another so as to communicate. Based on the earlier discussion there are two types of transfer; positive transfer which appears in correct language performance whereas negative transfer may lead to the occurrence of various mistakes. This might happen due to misunderstanding and misconception of the learners while trying to use target language. Languages are differ from each other and one of the factors attributed to the differences is the cross-cultural linguistics, which is each language has its own culture. This affects the learners during communication to use their own languages to put into the target languages. Therefor; language learning is not just learning some linguistic elements, but also it is learning a different culture besides learning linguistics elements. Pragmatic transfer is the fact that learners are unaware of knowledge of pragmatic of the target language or mainly the lack of such linguistic knowledge. It is crucially important that the EFL and ESL learners pay special attention to the fact that to avoid the negative transfer; they are in need of the awareness of pragmatic rules and how to use them in appropriate way, while trying to convey messages to the native speakers of the target language. Therefore, it is also necessary to the EFL or ESL teachers to take pragmatic features into consideration and teach culture besides language.

\section{REFERENCES}

[1] Blum-Kulka, S., House, J., \& Kasper, G. (1989). Cross-cultural pragmatics: Requests and apologies (Vol. 31). Ablex Pub.

[2] Crystal, D. (2003). Dictionary of linguistics and phonetics: Oxford: Blackwell.

[3] Ellis, R. (1994). The study of second language acquisition. Oxford: Oxford University.

[4] Franch, P. B. (1998). On pragmatic transfer. Universital de Valencia. In: studies in English Language and Linguistics.

[5] Helen Spencer-Oatey (2000). Culturally speaking: Meaning parrot through talk across culture. Great Britain: Piddles Ltd. King's Lynn Norfolk.

[6] Holmes, J (1992). An introduction to sociolinguistics. London: Longman.

[7] Jarvis, S., \& Pavlenko, A. (2008). Crosslinguistic influence in language and cognition. Abingdon: Routledge. 
[8] Kasper, G. (1992). Pragmatic transfer. Interlanguage studies bulletin (Utrecht), 8(3), 203-231.

[9] Leech, G. N. (1990). Principles of pragmatics ( $7^{\text {th }}$ ed.). London: Longman.

[10] Richards, J. C., \& Schmidt, R. W. (2013). Longman dictionary of language teaching and applied linguistics. (4th ed). New York: Routledge.

[11] Weinreich, U. (1953). Languages in contact: findings and problems. The Hague: Mouton.

[12] Whitley, M. S. (2002). Spanish/English contrasts: A course in Spanish linguistics. Georgetown University Press. 